\title{
Study of the indications for caesarean sections between 20 and 28 weeks of gestation
}

\author{
Sudha R. ${ }^{1}$, Anjali R. ${ }^{2 *}$

\begin{abstract}
${ }^{1}$ Associate Professor, ${ }^{2}$ Post Graduate Student, Department of Obstetrics and Gynecology, Cheluvamba Hospital, MMC
\end{abstract} \\ and RI, Mysore, Karnataka, India
}

Received: 06 January 2017

Revised: 18 January 2017

Accepted: 27 January 2017

\section{*Correspondence:}

Dr. Anjali R.,

E-mail: dr.anjaliramaswamy@gmail.com

Copyright: $\odot$ the author(s), publisher and licensee Medip Academy. This is an open-access article distributed under the terms of the Creative Commons Attribution Non-Commercial License, which permits unrestricted non-commercial use, distribution, and reproduction in any medium, provided the original work is properly cited.

\begin{abstract}
Background: Major change in the practice of obstetrics over the past century is progressive increase in the frequency of caesarean delivery and recent scientific information show improved survival or decreased morbidity for the neonate when caesarean delivery is performed for extreme prematurity. This study was done to determine the caesarean section rate for sections done between 20 and 28 weeks of gestation and to analyze the indications for such sections.

Methods: Institutional based retrospective observational study done in the Obstetrics and Gynaecology Department, Cheluvamba Hospital, MMC\&RI, Mysore, Karnataka, India. Caesarean sections done over 5 years from January $1^{\text {st }}$ 2010 till December $31^{\text {st }} 2014$ are considered for the study. The total number of Caesarean sections done for gestational age between 20 and 28 weeks are noted. The data obtained is analyzed for the indications at the respective gestational ages.

Results: Frequency of caesarean section at gestational age between 20 and 28 weeks is seen to be $<1 \%$. Out of total 15,906 LSCS cases, 97 (0.6\%) patients under went caesarean section between 20 and 28 weeks of gestation. Of the 97 cases, 54 cases $(55.67 \%)$ were operated at 28 weeks, 17 cases $(17.52 \%)$ at 26 weeks, 20 cases $(20.61 \%)$ at 24 weeks, 4 cases $(4.12 \%)$ at 22 weeks and 2 cases $(2.06 \%)$ at 20 weeks of gestation. APH in $33(34.0 \%)$, pre-ecclampsia and ecclampsia in $30(30.9 \%)$ cases are found to be the indications for delivery in 61 cases $(64.9 \%)$. The indications for caesarean sections in $44(45.3 \%)$ cases were previous caesarean section associated with or without pre-ecclampsia and APH as contributory factors.

Conclusions: Caesarean section rate for gestational age between 20 and 28 weeks' gestational age is $<1 \%$ and there is decreasing trend. Previous caesarean section, APH, ecclampsia and pre-ecclampsia with their complications are the common indications for such sections. The decision to perform first caesarean section and the indication for it is of prime importance.
\end{abstract}

Keywords: Caesarean section, Hysterotomy, Prematurity

\section{INTRODUCTION}

Labour and birth should take into account the mother's preferences, her medical condition and previous intrapartum history. Women should be strongly advised to take immediate steps towards delivery if there is sepsis, preeclampsia, placental abruption or membrane rupture, but a more flexible approach can be discussed if these factors are not present. Vaginal birth is the recommended mode of delivery for most women, but caesarean birth would need to be considered with some. ${ }^{1}$

A combination of factors has provided the impetus to review the topic regarding the proper course of action 
when a woman presents with preterm labour at an extremely preterm gestational age. These factors include a rising rate of caesarean delivery and recent scientific information purporting to show improved survival or decreased morbidity for the neonate when caesarean delivery is performed for extreme prematurity. ${ }^{2}$

Major change in the practice of obstetrics over the past century is progressive increase in the frequency of caesarean delivery. The advent of better anaesthesia; safety of lower uterine segment technique and prophylactic antibiotics, the broadening of indication for operation, the recognition of fetus as a patient and the acceptance of this procedure by women have characterized the evolution of caesarean birth in the $20^{\text {th }}$ century. Today the previous caesarean section is the main contributory factor for this high frequency of caesarean delivery worldwide. The secondary rise in repeat caesarean delivery has been associated with an increase in severe complications particularly the complication of placentation like placenta praevia and placenta accrete which in turn increases the maternal morbidity and even mortality. So, the decision to perform first caesarean section is of prime importance. . $^{3,4}$

\section{METHODS}

It was an Institutional based retrospective observational study done in the Obstetrics and Gynaecology Department, Cheluvamba Hospital, MMC\&RI, Mysore, Karnataka, India. Caesarean sections done between 20 and 28 weeks of gestation, over 5 years from January $1^{\text {st }}$ 2010 till December $31^{\text {st }} 2014$ are considered for the study. The total number of caesarean sections done over 5 years and the number of such sections for gestational age between 20 and 28 weeks were noted. The data obtained regarding these caesarean deliveries were analysed for their indications at the respective gestational ages.

Gestational age was based on the best estimate using information on last menstrual period and ultrasound investigation. The cases were studied to analyse the factors that lead for termination of the pregnancy like preterm labour, preterm premature rupture of membranes, pre-ecclampsia, ecclampsia and its complications like HELLP syndrome, abruption, bleeding placenta previa, intrauterine fetal demise and other less common factors.

The indications for caesarean deliveries in such preterm babies were categorized as previous caesarean sections in labour, failed inductions in cases of PPROM, anomalous babies, intra uterine fetal demise and hypertension in pregnancy cases, breech presentation, bleeding placenta previa, conjoint twins, transverse lie and other rare causes like pelvic bone fractures.

\section{RESULTS}

Of the 15,906 infants born by caesarean section in the study period, $97(0.60 \%)$ were born at gestational ages between 20 and 28 weeks of gestation. In 2010 the number of such sections was 21 out of 2647 cases (0.79\%), 2011- 25 out of 2520 cases $(0.99 \%), 2012-23$ out of 3284 cases $(0.70 \%), 2013-16$ out of 3641 cases $(0.43 \%)$ and in $2014-12$ out of 3814 cases $(0.28 \%)$. Overall there was a decreasing trend with less number of extremely preterm babies being delivered by caesarean sections (Figure 1 and 2).

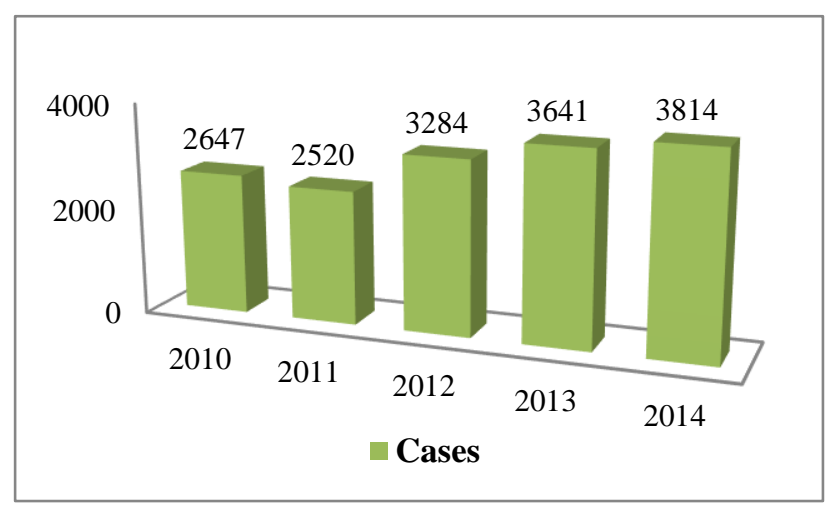

Figure 1: Total number of LSCS per year.

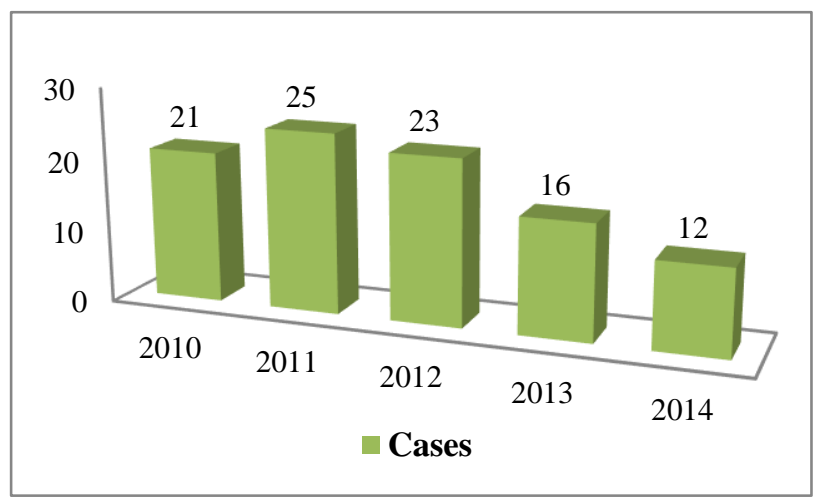

Figure 2: Total number of caesarean sections between 20 and 28 week of gestation per year.

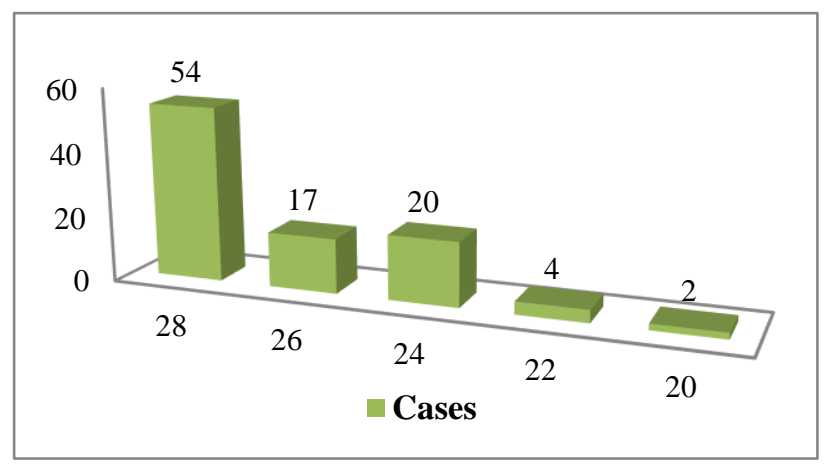

Figure 3: Number of caesarean sections between 20 and 28 weeks of gestation distributed according to gestational ages.

Out of 97 caesarean sections that happened between 20 and 28 weeks of gestation, 54 cases were at gestational age of 28 weeks $(55.67 \%), 17$ cases at 26 weeks 
(17.52\%), 20 cases at 24 weeks $(20.16 \%), 4$ cases at 22 weeks $(4.62 \%)$ and 2 cases at 20 weeks of gestation. It can be noted that the number of cases decline with lesser gestational age (Figure 3).

Among the 97 cases included in the study, 33 cases (34.0\%) had APH (antepartum haemorrhage)- placenta previa or abruption, 30 cases $(30.9 \%)$ was associated with pre-ecclampsia, ecclampsia and its complications. Together, APH and hypertension in pregnancy contribute nearly $64.9 \%$ of the study cases. Other factors that led for termination of pregnancy were anomalous babies in 14 cases $(14.4 \%)$, intra-uterine fetal demise in 11 cases (11.3\%), PPROM in 7 cases $(7.2 \%)$ and other rare cases like fracture of pelvic bones (Figure 4).

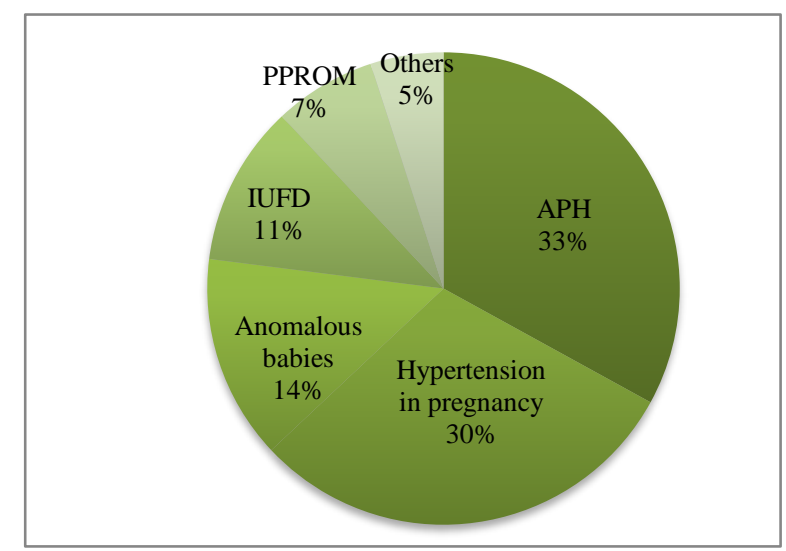

Figure 4: Indications for caesarean sections between 20 and 28 weeks of gestation.

Previous caesarean section was seen as the indication for the present caesarean section in 44 cases $(45.3 \%$ ) (Figure $5)$.

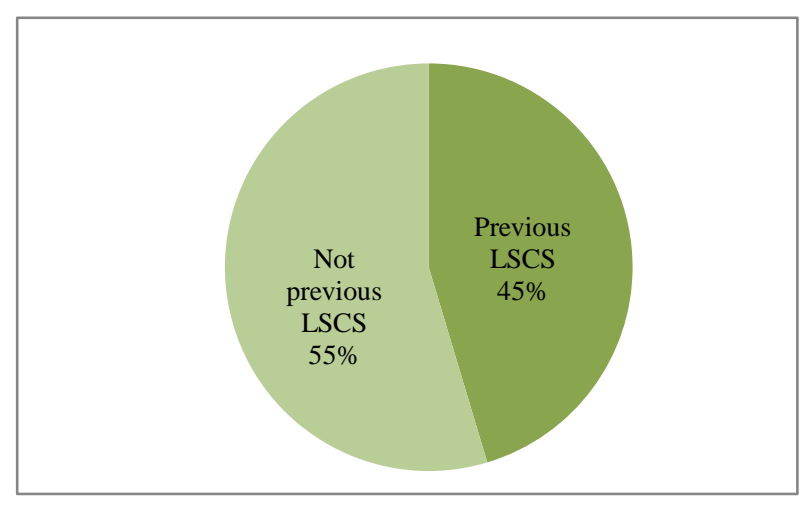

Figure 5: No of previous LSCS cases.

\section{DISCUSSION}

The decision to perform a caesarean delivery at 20 to 28 weeks of gestation is complex because maternal, fetal, and neonatal morbidity and mortality risks must be considered. Because mode of delivery is influenced by fetal and maternal conditions, differences in the infant mortality rate between vaginal births compared with caesarean delivery are not surprising. ${ }^{5-8}$ However, data on whether all extremely preterm infants would benefit from a caesarean delivery are unclear. ${ }^{7-9}$

Despite the uncertainty of benefit, caesarean deliveries for infants between 20 and 28 weeks' gestation is common as the survival has improved. ${ }^{10}$ There has been a steady increase in the rate of caesarean section in both developed and developing countries. This rising rate has become an international public health concern worldwide. ${ }^{11}$ In present study also there was a steady increase in the number of caesarean deliveries over the 5 years of study period. In the present study caesarean section rate at gestational ages between 20 and 28 weeks of gestation was found to be $0.6 \%$. We found a decrease in the frequency of caesarean sections of extremely preterm babies from $0.79 \%$ in 2010 to $0.28 \%$ in 2014 . With lesser gestational ages the number of cases in need of caesarean deliveries was seen to be lesser; highest number of cases was being at 28 weeks of gestation and lowest being at 20 weeks.

Hypertensive disorders accounted for $30.9 \%$ of caesarean section in this study. Good antenatal care can detect such problems earlier and an early management can prevent complications. These high-risk cases should be assessed on risk/benefit ratio and caesarean section should be done only for definite obstetrical indication. ${ }^{12}$

Placenta praevia and abruption together i.e. APH contributed for $34.0 \%$ of caesareans in our study. Vaginal delivery is contra-indicated in placenta praevia cases. So, these were unavoidable operation. In cases of abruption also caesarean deliveries may become necessary to accelerate the delivery.

Analysis of indications revealed that $45.3 \%$ patients had previous section. After one caesarean section there is $67 \%$ chance of having repeat caesarean delivery. The reluctance to permit a trial of labour following one LSCS is probably due to two main factors. Firstly, there is fear of uterine rupture in labour which is 5.2/1000 VBAC compared with $(1.6 / 1000)$ planned repeat caesarean delivery and it can be catastrophic leading to perinatal death (1/2000) and very rarely maternal death. ${ }^{13,14,15}$ Secondly, many obstetrician and women considered that caesarean is a convenient procedure, free of hazards while failed VBAC is associated with $14.1 \%$ maternal morbidity than $3.6 \%$ with planned repeat caesarean delivery. ${ }^{16}$

In present study, they had repeat caesarean section because many patients had caesarean sections without proper documentation of indication and type of uterine scar. Additionally, most of these ladies have interpregnancy interval less than one year coupled with trial of labour outside the hospital making further trial risky, so repeat caesarean section performed. Large family size, high perinatal mortality, desire for male baby, refusal of 
BTL on religious grounds may be contributing factors for high order repeat caesarean section. Increased rate of emergency caesarean section increase complications in labouring women in present and future pregnancy.

Failure to progress was third major indication contributing of caesarean section. Failure to progress is an ill-defined terminology, lack of dilatation or descents of presenting part are often over diagnosed without monitoring partogram. Thus, in every case it would be ideal to monitor progress according to partogram for decreasing the rate of caesarean section. ${ }^{17}$

So, to avoid major burden of patient with previous caesarean section decision of first operation should be done by well-trained person after full trial of labour on individualized basis. ${ }^{17}$

\section{CONCLUSION}

Present study concludes that repeat caesarean sections are mainly responsible for high caesarean section rate. Attempts should be made to decrease this by critical evaluation of decision to perform first operation and considering careful trial of labour in patients with previous one caesarean section. Research with prospective data collection is needed to further delineate the short and long-term benefits and risks of attempted route of delivery in the early preterm gestation.

\section{Funding: No funding sources}

Conflict of interest: None declared

Ethical approval: The study was approved by the Institutional Ethics Committee

\section{REFERENCES}

1. The RCOG Green-top Guideline No.55. Late intrauterine fetal death and stillbirth. 2010.

2. Skupski DW, Greenough A, Donn SM, Bancalari E, Vladareanu R. Delivery mode for the extremely preterm fetus: a statement of the prematurity working group of the World Association of Perinatal Medicine. J Perinat Med. 2009;37:583-6.

3. Gilliam M, Rosenberg D, Davis F. The likelihood of placenta praevia with greater number of caesarean deliveries and higher parity. Obstet Gynecol. 2000; 99:976-80.

4. Gielchinsky Y, Rojansky N, Fasouliotis SJ, Ezra Y. Placenta accrete- summary of 10 years: A survey of 310 cases. Placenta. 2002;23:210-4.

5. Muhuri PK, MacDorman MF, Menacker F. Method of delivery and neonatal mortality among very low birth weight infants in the United States. Maternal Child Health J. 2006;10:47-53.

6. Wylie BJ, Davidson LL, Batra M, Reed SD. Method of delivery and neonatal outcome in very low-birth weight vertex-presenting fetuses. Am J Obstet Gynecol. 2008;198:640.

7. Jonas HA, Khalid N, Schwartz SM. The relationship between Caesarean section and neonatal mortality in very-low-birthweight infants born in Washington State, USA. Paediatr Perinat Epidemiol. 1999;13:170-89.

8. Malloy MH. Impact of cesarean section on neonatal mortality rates among very preterm infants in the United States, 2000-2003. Pediatrics. 2008;122:28592.

9. Redman ME, Gonik B. Cesarean delivery rates at the threshold of viability. Am J Obstet Gynecol. 2002;187:873-6.

10. MacDorman MF, Declercq E, Zhang J. Obstetrical intervention and the singleton preterm birth rate in the United States from 1991-2006. Am J Public Health. 2010;100:2241-7.

11. Christilaw JE. Caesarean section by choice constructing a reproductive right framework for the debate. Int J Gynaecol Obstet. 2006;94(3):262-8.

12. Chanthasenanont A, Pongrojpaw D. Indications for Caesarean section at Thammasat University Hospital. J Med Assoc Thai. 2007;90:1733-7.

13. Lydon-Rochelle M, Holt VL, Easterling TR, Martin DP. Risk of uterine rupture during labor among women with a prior caesarean delivery, N Engl J Med. 2001;345:3-8.

14. Mozurkewick EL. Hutton EK. Elective repeat caesarean delivery versus trial of labor: A metaanalysis of literature from 1989 to 1999 . Am J Obstet Gynecol. 2000;183:1187-97.

15. Rageth JC, Juzi C, Grossenbecher H. Delivery after previous caesarean: A risk evaluation. Swiss working group of Obstetrics and gynecologic Institutions. Obstet Gynecol. 1999;93:332- 7.

16. Wen SW, Rusen ID, Walker M, Liston R, Kramer MS, Baskett T. Comparison of maternal mortality and morbitity between trial of labor and caesarean section among women with previous caesarean delivery. Am J Obstet Gynecol. 2004;191(4):1263-9.

17. Rafique $S$, Raana $G$ Changing trends in caesarean section rate and indications. Pak $\mathrm{J}$ Surg. 2012;28(1):60-4.

Cite this article as: Sudha R, Anjali R. Study of the indications for caesarean sections between 20 and 28 weeks of gestation. Int J Reprod Contracept Obstet Gynecol. 2017;6:787-90. 